\title{
O DESENHO NO PROCESSO DE GERAÇÃO DE CONCEPÇÕES DE PROJETO
}

\author{
Eduardo Cardoso \\ Universidade Federal do Rio Grande do Sul - UFRGS \\ eduardo.cardoso@ufrgs.br \\ Sérgio Leandro dos Santos \\ Universidade Federal do Rio Grande do Sul - UFRGS \\ sergio.santos@ufrgs.br \\ Stefan von der Heyde Fernandes \\ Universidade Federal do Rio Grande do Sul - UFRGS \\ stefanufrgs@gmail.com \\ Tânia Luisa Koltermann da Silva \\ Universidade Federal do Rio Grande do Sul - UFRGS \\ tania.silva@ufrgs.br \\ Fábio Gonçalves Teixeira \\ Universidade Federal do Rio Grande do Sul - UFRGS \\ fabiogt@ufrgs.br \\ Régio Pierre da Silva \\ Universidade Federal do Rio Grande do Sul - UFRGS \\ regio.silva@ufrgs.br
}

\begin{abstract}
Resumo: 0 presente artigo visa apresentar conceitos gerais para o embasamento teórico e metodológico acerca do emprego de desenhos no processo de geração de concepções de projeto. Esta pesquisa ocorreu no período de seis meses, utilizando os procedimentos metodológicos propostos para teste e avaliação do uso de desenhos como ferramenta de apoio à geração de concepções de projeto em diferentes fases do processo de desenvolvimento de produtos. Para tanto, apresenta-se uma aplicação prática à partir de um problema de projeto. A partir da revisão bibliográfica realizada acerca dos processos criativos, das técnicas de criação e do emprego de desenhos no PDP é possível evidenciar a contribuição da representação gráfica ao longo de todo processo de projeto como mecanismo de criação, expressão, reflexão, refinamento e comunicação.
\end{abstract}

Palavras-chave: projeto, geração de concepções, desenho. 


\begin{abstract}
This article presents general concepts for the theoretical and methodological background about the use of drawings in the generation of project concepts process. This research took place within six months, using the proposed methodological procedures for testing and evaluating the use of drawings as a support tool to the generation of project concepts at different stages of the product development process. To this end, we present a practical implementation starting from a design problem. From the literature review about the creative process, the creative techniques and the use of drawings in the PDP is possible to demonstrate the contribution of graphical representation throughout the entire design process as a mechanism of creation, expression, reflection, refinement and communication.
\end{abstract}

Keywords: design, concepts generation, drawing.

\title{
1. INTRODUÇÃO
}

Primeiramente faz-se necessário uma contextualização sobre o desenvolvimento do presente trabalho, assim como a apresentação de alguns conceitos gerais acerca da temática proposta para posterior aprofundamento. 0 embasamento teórico da pesquisa é estabelecido a partir dos trabalhos de Back et al. (2008), Löbach (2001), Baxter (2000) e Bom Fim (1995) sobre as técnicas de criação no processo de desenvolvimento de produtos (PDP); das obras de Gomes (2004; 2011), Ostrower (2010), Gardner (2005), Boden (1999), Alencar (1996), Kneller (1978), Novaes (1971) e De Bono (1970), entre outros, sobre criatividade e processo criativo. Além de Pipes (2010), Suwa (2009), Tversky (2003) e Schön (2000) sobre desenho.

Enquanto a aplicação prática, compreendeu o emprego de desenhos em uma ferramenta de criação para geração de concepções de projeto - matriz morfológica - à partir de um problema não estruturado: o transporte urbano de crianças de 0 a 1 anos em curtas distâncias, conforme será detalhado nos procedimentos metodológicos.

A discussão proposta envolve primordialmente o desenho como ferramenta de expressão, comunicação e criação para a geração de concepções de projeto no PDP. Discute-se ainda a forma como se empregam desenhos e os momentos e objetivos no PDP, assim como os resultados obtidos.

\section{CRIATIVIDADE E PROCESSO CRIATIVO}

Por muito tempo a criatividade foi vista como algo divino, os músicos, poetas e artistas não produziam suas obras através de seu próprio esforço, eles eram inspirados por um poder "super-humano" (NOVAES, 1971). Platão expressou que o artista no momento da criação perdia o controle de si mesmo, sendo coordenado por um poder superior (KNELLER, 1978). Da mesma forma, até o século XIX a criatividade era vista como algo que surgia inconsciente. Sigmund Freud sustentou que o artista encontrava na arte uma forma de exprimir os conflitos interiores entre o consciente e o inconsciente em uma linha tênue entre a criatividade e a neurose (KNELLER, 1978).

Ao longo dos anos, diversos pesquisadores, como Joy Paul Guilford, precursor no desenvolvimento do pensamento divergente, Howard Gardner, introdutor dos 
estudos sobre inteligências múltiplas, George Frederick Kneller, pesquisador das características da criatividade, e Ellis Paul Torrance, criador de diferentes formas de avaliar a criatividade nos indivíduos, desmistificaram as propriedades e analisaram de forma científica este tema.

Etimologicamente, criatividade está ligada ao termo criar, que significa dar existência, sair do nada, estabelecer relações até então não estabelecidas pelo indivíduo (NOVAES, 1971). Segundo Alencar (1996) a criatividade está associada ao processo de pensamento relacionado à imaginação, invenção, inovação intuição, inspiração, iluminação e originalidade. Para Kneller (1978) o termo significa um grupo de capacidades relacionadas, como fluência, originalidade e flexibilidade. Já para Ostrower (2010) criar é formar, sendo, portanto, um potencial inerente ao homem e algo indispensável às suas necessidades existenciais.

Para o Lubart (2007) a criatividade é a capacidade de realizar uma produção que seja, ao mesmo tempo, nova e adaptada ao contexto na qual ela se manifesta. Esta produção nova é original e imprevista, se diferenciando de qualquer outra solução já anteriormente criada por outras pessoas (LUBART, 2007). Ao mesmo tempo, a produção criativa não pode ser simplesmente nova, original ou imprevista, mas, também, útil no seu contexto (BODEN, 1999; LUBART, 2007). Isto significa que a ideia deve ser igualmente relevante e útil para que atenda as necessidades das pessoas.

Assim como a criatividade, para Löbach (2001) a configuração de um produto não se dá em um ambiente vazio, cada objeto de design é o resultado de um processo de desenvolvimento. Isto exige do profissional a habilidade de associar o seus conhecimentos e experiências com o problema de projeto, tornando a sua solução útil, original e inovadora para o contexto em que se insere (LÖBACH, 2001).

O designer deve ter como competência a "capacidade criativa para propor soluções inovadoras, utilizando domínios de técnicas e de processos de criação" (DIRETRIZES CURRICULARES NACIONAIS DO CURSO DE GRADUAÇÃO EM DESIGN, 2004, p. 2). Além disso, De Bono (1970) introduziu também o termo pensamento lateral, criado para designar o pensamento que se mostra contrário aos procedimentos de processos lógicos de pensamento, chamados por ele de pensamento vertical. Para o autor, a criatividade não parece estar relacionada com pura inteligência lógica ou matemática, mas sim com um hábito, com um modo especial de pensar. De Bono (1970) utiliza a analogia de cavar buracos para explicar a diferença entre os pensamentos, sendo um único buraco profundo referente àquela forma de resolução de problemas com apenas uma resposta, enquanto os diversos buracos rasos, a tentativa divergente de achar diferentes alternativas para a solução de um problema complexo.

Outra forma de pensamento não linear é o pensamento visual (ARNHEIM, 1997). Proveniente da teoria da Gestalt, Arnheim (1997) acreditava que pensamos em forma de imagens, pois percebemos o mundo da mesma forma. A análise puramente verbal e escrita do contexto limita a capacidade, e a pouca percepção visual resulta na dificuldade de desenvolver novas soluções.

O indivíduo criativo é, portanto, aquele que não se limita em seguir a linha escrita para elaborar, expressar e desenvolver seu pensamento, limitando-se ao pensamento vertical. Para Gomes (2004) as habilidades do designer estão tanto nas técnicas e processos que utiliza como metodologia, quanto na habilidade de gerar 
conhecimento, transformar o contexto e projetar novas soluções para os problemas em que vive de forma criativa.

\subsection{0 processo criativo}

Para Alencar (1996), o desafio de aliar alta qualidade e baixo custo frente às exigências cada vez maiores dos usuários, tem sido um dos fatores contribuintes para despertar a consciência das organizações para o potencial criativo de seus recursos humanos. Esta competitividade também exige do designer a capacidade de projetar produtos inovadores em espaços de tempo cada vez mais curtos. Por isso, métodos para aperfeiçoar o PDP foram desenvolvidos nas últimas décadas, através de autores que abordam as técnicas etapas de metodologias de projeto (BACK et al. 2008; BAXTER, 2000; BOMFIM, 1995; LÖBACH, 2001).

Segundo Back et al. (2008) um procedimento de projeto pode ser dividido em três grandes fases que são subdivididas. A primeira fase consiste no planejamento de projeto, em que é feita a definição do escopo de projeto e do produto. A segunda macrofase é a elaboração do projeto do produto, que envolve a elaboração do projeto do produto e de plano de manufatura. Por fim, a fase de implementação envolve a execução do plano de manufatura na produção da empresa e o encerramento do projeto (BACK et al., 2008).

Porém, apenas a utilização de uma metodologia específica de desenvolvimento de produto não assegura que a empresa será capaz de apresentar ao mercado produtos inovadores. Baxter (2000) salienta que atualmente já não é possível escolher entre querer ou não inovar, as empresas precisam inovar, caso contrário, são pressionadas pela concorrência e pela obsolescência cada vez mais rápida dos seus produtos. Ao mesmo tempo, as empresas mesmo buscando a inovação fracassam, pois não encontram em seus funcionários as características necessárias para resultar em produtos inovadores (ALENCAR, 1996).

Por isso, além do conhecimento no PDP, a empresa e seus profissionais devem compreender o processo criativo (ALENCAR, 1996). Apesar de ser um tema recente na área do design, o estudo do processo criativo é a muito tempo analisado na área da psicologia. Um dos primeiros autores a propor um processo de criatividade foi Wallas (1926, apud. KNELLER, 1978) que classificou em preparação, incubação, iluminação e verificação como o ciclo criador pode ser dividido. Posteriormente, muitos autores contribuíram para identificar e classificar as etapas criativas. Back et al. (2008) classifica o processo de geração de concepções ou de criação em seis etapas: 1)Preparação; 2)Esforço Concentrado; 3)Afastamento; 4)Visão; 5)Seleção das ideias; 6)Revisão.

Gomes (2004) destaca que mesmo havendo propostas diferentes na utilização dos termos, em um ponto, os principais autores são unânimes quanto às características das principais etapas criativas, segmentadas por ele em identificação, preparação, incubação, esquentação, iluminação e verificação.

Assim como a criatividade pode ser identificada por características humanas como fluência, flexibilidade, originalidade, elaboração, sensibilidade para problemas (ALENCAR, 1996), e estas são desenvolvidas através de diferentes formas de pensamentos, como, por exemplo, pensamento visual (ARNHEIM, 1997), pensamento lateral (DE BONO, 1970), pensamento divergente (GUILFORD, 1967, 1979 apud. ALENCAR, 1996), a prática do desenho pode contribuir para o desenvolvimento da 
criatividade e do processo criativo. Para Pipes (2010) o desenho é o meio fundamental de exteriorizar ideias e, então, comunicá-las para outros membros da equipe de design. Com isso, através da representação gráfica das ideias uma equipe de projeto pode aumentar suas capacidades criativas.

\section{O DESENHO NO PROCESSO DE PROJETO}

Bem como salienta Baxter "A criatividade é o coração do design, em todos os estágios do projeto" (BAXTER, 2000. p. 51). Devido a grande concorrência entre os produtos atuais, a competição apenas por preço torna-se cada vez mais difícil, e o designer tem papel crucial para propor novos diferencias para estes produtos. Para Baxter (2000) não é necessário gerar uma inovação radical a cada novo lançamento, até porque poucas empresas estariam dispostas a correr este risco de investimento. É necessário, no entanto, que os designers consigam projetar soluções eficazes e que sejam percebidas pelos usuários. Para isso, é necessária a prática da criatividade em todos os estágios de desenvolvimento do produto, desde a identificação de uma oportunidade até o detalhamento final para produção (BAXTER, 2000).

O desenho, assim como a criatividade, também acompanha todas as etapas de projeto de um produto, podendo da mesma forma ser compreendido como processo (PIPES, 2010). Podemos identificar o desenho em toda a sequência do processo de design, desde os esboços iniciais, em que a equipe de design busca soluções para o problema que satisfaça as restrições e requisitos do projeto; passando pelos desenhos de representação e visualização para apresentação da proposta aos clientes ou aos outros setores da empresa; seguindo aos desenhos de detalhamento; aos desenhos de engenharia para produção; e por fim os desenhos utilizados para publicidade e instrução ao usuário final na montagem e operação do produto (PIPES, 2010).

Ao mesmo tempo em que o desenho é uma ferramenta utilizada em todas as etapas do projeto, suas características e definições se tornam complexas pelo motivo de sua abrangência. Gomes (2011) explica que o desenho possui diferentes funções e finalidades no processo criativo de desenvolvimento dos produtos. Para o autor, o designer deve saber expressar-se dentro das diferentes ações gráficas, definidas por ele como: Desenho Expressional, fundamental para a exploração de novas ideias e criação de formas; Desenho Operacional, crucial para fixação de convenções técnicoindustriais, definição geométrico-organizacional de um projeto, mimese e imitação gráfico-visual de um produto; Desenho Projetual, abrangente e ramificado por campos do desenho de ambientes, de comunicação e de artefatos.

Pei et al. (2011) apresenta uma taxonomia das representações gráficas no design, dividindo e explicitando as funções de cada tipo de desenho, sendo dividido em Sketches aquele tipo de desenho voltado para a criação de alternativas na fase de conceituação e em Drawings, os desenhos criados pela engenharia na fase de detalhamento. Mais especificamente, dentro da fase de conceituação, o autor ainda sub divide os tipos de desenho em Personal Sketches, desenhos pessoais para a reflexão do indivíduo sobre as suas ideias, Shared Sketches, desenhos compartilhados que visam a troca de ideias e soluções, Persuasive Sketches, que visam a comunicação, bem como o Handover Sketches, que contemplam os desenhos em vistas explodidas e em cortes para apresentar melhor as soluções (PEl, et al. 2011).

Neste trabalho, será abordado o desenho para geração de alternativas, utilizado na etapa de projeto conceitual definida na metodologia de Back et al. (2008). 
Pipes (2010) caracteriza o desenho utilizado nesta fase do projeto de produto não apenas como um meio de expressão, ou comunicação de nossas ideias aos demais membros da equipe de projeto, mas o desenho nesta etapa serve também para exteriorizar os pensamentos e torna-los concretos (PIPES, 2010).

Os esboços de conceito não requerem muitos recursos financeiros, podendo ser produzidos apenas com papel e caneta, mas muitas vezes requer uma explicação verbal ou escrita do designer sobre a sua representação gráfica (PIPES, 2010). Tversky \& Suwa (2009) explicam os motivos do uso deste tipo de desenho para geração de alternativas. O sketch (esboço) é uma forma de expressão rápida, desta forma propicia com agilidade a tentativa e erro, são fáceis de criar e simples de rever; permitem trabalhar com partes isoladamente; fornecem perspectivas e escalas diferentes; além disso, os designers podem trabalhar com o sketch focando em aspectos do projeto e ignorando os aspectos que possam lhe distrair ou confundir (TVERSKY \& SUWA, 2009). As autoras comparam como seria catastrófico para o processo criativo e, consequentemente para o processo de projeto, se o uso do esboço fosse substituído pelo mock-up ou protótipos. A produção de modelos físicos para gerar alternativas teriam desvantagens por exigirem perfeições em sua completude, na lenta geração e reformulação dos protótipos, e na dificuldade de expressar em três dimensões algo que ainda está vago e parcial (TVERSKY \& SUWA, 2009).

Além disso, o desenho permite ao designer descobrir novas relações que não haviam sido anteriormente expressas, para Schön (2000) o designer cria o desenho para representar um conjunto de elementos, padrões e restrições, mas, ao mesmo tempo, ao estudar o desenho e analisá-lo, vê outros e novos elementos, relações e padrões, contribuindo para o que o autor chama de "reflexão-na-ação".

A reflexão-na-ação é justamente o que o designer realiza quando está desenvolvendo o desenho para geração de novas ideias, ou seja, consiste em refletir através dele, sem interrompê-lo. O pensamento dá forma ao desenho, e ao mesmo tempo em que o faz, reflete sobre os seus resultados, gerando cada vez mais novos desenhos enriquecendo as alternativas de soluções (SCHÖN, 2000).

\section{TÉCNICAS DE CRIAÇÃO NO PROCESSO DE DESENVOLVIMENTO DE PRODUTOS}

O PDP requer conhecimentos técnicos e teóricos para obtenção de bons resultados. O processo, ao mesmo tempo em que é preciso ser flexível deve possibilitar o seu planejamento, otimização e avaliação. Assim, deve ser sistematizado, o que não quer dizer que deixa de lado a intuição e o repertório pessoal e profissional. Ao contrário, o uso de procedimentos sistematizados pode potencializar a inventividade e capacidade dos projetistas ao guiá-los ao mesmo tempo em que possibilita a avaliação objetiva dos resultados (PAHL e BEITZ, 1996).

Desta forma, uma vez que se tenham as especificações de projeto, a etapa seguinte é a geração de soluções alternativas para o problema de projeto, que podem ser comparadas e combinadas, permitindo a seleção da melhor e mais inovadora concepção do produto.

A geração de alternativas é um processo criativo e para que seja bem sucedido, Back (et al. 2008) recomenda o uso de métodos ou procedimentos que permitam que um conjunto de soluções inovadoras sejam obtidas de forma rápida. Para o autor, estes métodos podem ser classificados em: métodos intuitivos e métodos sistemáticos. 
Dentre os métodos intuitivos, os mais usados são: Brainstorming e suas variações, como Brainwriting, o método 635 e o Brainstorming eletrônico; método Delphi; Analogias Direta, Simbólica e Pessoal; método Sinético; e método da Instigação de Questões (MESCRAI).

\section{Quadro 01: métodos intuitivos de Geração de Alternativas.}

\begin{tabular}{|c|c|}
\hline Brainstorming & $\begin{array}{l}\text { O termo sugere uma tempestade de ideias. Criado por Alex F. Osborn em 1953, é } \\
\text { geralmente realizado em grupo (de } 5 \text { a } 10 \text { pessoas) e coordenado por um líder que } \\
\text { deve explicar o problema e orientar a sessão, mas também pode ser usado por um } \\
\text { indivíduo apenas. As ideias devem ser registradas para serem reavaliadas } \\
\text { posteriormente (BAXTER, 1998). Deve-se seguir algumas orientações: Funciona } \\
\text { melhor com integrantes do grupo com formações variadas; O tempo de reunião } \\
\text { não deve ultrapassar } 50 \text { minutos; Deve-se evitar críticas ou avaliações prematuras; } \\
\text { O objetivo é gerar o máximo possível de soluções, sem questionar sua viabilidade. }\end{array}$ \\
\hline Brainwriting & $\begin{array}{l}\text { Variação do anterior, busca reduzir seus pontos fracos sem abrir mão de suas } \\
\text { vantagens. Os participantes escrevem suas ideias individualmente para depois } \\
\text { compartilhar com o grupo pra um estímulo adicional. As ideias também podem ser } \\
\text { representadas por desenhos simples. (BAXTER, 1998). }\end{array}$ \\
\hline $\begin{array}{l}\text { Brainstorming } \\
\text { eletrônico }\end{array}$ & $\begin{array}{l}\text { No meio eletrônico o trabalho deve ser executado via internet. A vantagem é que as } \\
\text { ideias podem ser obtidas e compartilhadas de participantes que não poderiam estar } \\
\text { juntos em uma reunião física (BACK et al. 2008). }\end{array}$ \\
\hline Método 635 & $\begin{array}{l}\text { Consiste em uma equipe de seis membros, onde cada membro registra numa folha } \\
\text { três sugestões de solução. Em seguida, cada pessoa passa sua folha para a próxima, } \\
\text { que deverá acrescentar três novas sugestões ou melhoramentos, desenvolvendo as } \\
\text { ideias anteriores. Repete-se até que cada folha tenha passado pelos outros cinco } \\
\text { membros da equipe. Considerando que todos os membros foram criativos e sem } \\
\text { ideias repetidas, ao final teria-se o potencial para obter } 108 \text { alternativas. }\end{array}$ \\
\hline $\begin{array}{l}\text { Método } \\
\text { Delphi }\end{array}$ & $\begin{array}{l}\text { Desenvolvido pela empresa Rand Corporation, em 1950, visa coletar opiniões de um } \\
\text { grupo de especialistas através de um questionário estruturado. Originalmente, } \\
\text { efetuado por correspondência em rodadas sucessivas, mas pode acontecer por } \\
\text { meios eletrônicos de trabalho colaborativo. Após identificar o problema, os } \\
\text { especialistas são consultados em três rodadas sucessivas. Na primeira, os } \\
\text { profissionais respondem as questões do questionário estruturado, apresentando } \\
\text { uma visão mais geral sobre o assunto. O segundo é preparado com base nas } \\
\text { primeiras respostas com objetivo de esclarecer alguns aspectos, identificar áreas de } \\
\text { discordância e concordância, estabelecer prioridades e identificar e selecionar } \\
\text { soluções alternativas sugeridas nas primeiras respostas. As respostas do segundo } \\
\text { questionário são novamente analisadas para a preparação do terceiro que tem o } \\
\text { propósito de obter um consenso sobre os aspectos do problema e a escolha da } \\
\text { melhor solução. Este ciclo é repetido até que se obtenha a solução do problema. }\end{array}$ \\
\hline Analogias & $\begin{array}{l}\text { Forma de raciocínio, em que propriedades de um objeto são transferidas para outro } \\
\text { objeto diferente, mas com aspectos em comum. Elas podem ser usadas para criar } \\
\text { soluções completamente novas, descobrindo-se como um problema semelhante é } \\
\text { resolvido em um contexto diferente (BAXTER, 1998). Back (et al. 2008) classifica as } \\
\text { analogias em três tipos: Analogia direta; Analogia simbólica (transforma-se o } \\
\text { problema em um verbo, em seguida se busca por sinônimos); Analogia pessoal (ou } \\
\text { empatia, consiste em colocar-se na posição do outro, analisando o problema sob } \\
\text { outro ponto de vista). }\end{array}$ \\
\hline $\begin{array}{l}\text { Método } \\
\text { Sinético }\end{array}$ & $\begin{array}{l}\text { O termo Sinética é derivado do Grego e significa juntar elementos diferentes, } \\
\text { aparentemente não relacionados entre si (BAXTER, 1998). A sinética reconhece dois } \\
\text { tipos de mecanismos mentais, transformar o estranho em familiar e transforma o } \\
\text { familiar em estranho e faz uso das analogias. Consiste em: Formulação do } \\
\text { problema; Analise do problema; Aplicação das analogias; Desenvolvimento da } \\
\text { analogia; Aplicação da solução análoga; Avaliação da solução análoga; Busca por } \\
\text { alternativas (BACK et al. 2008). }\end{array}$ \\
\hline
\end{tabular}


Método de Instigação de Questões MESCRAI
Utiliza uma série de palavras-chave para ativar ou estimular ideias para melhorar produtos ou processos. Baxter (1998) denomina o método de MESCRAI, que é uma sigla de "Modifique, Elimine, Substitua, Combine, Rearranje, Adapte, Inverta". Estes termos funcionam como uma lista de verificação para possíveis mudanças nos produtos.

Os métodos intuitivos são muito úteis para disparar a geração de ideias na fase do projeto conceitual e também em fases posteriores do projeto. Existem ainda outros métodos classificados como sistemáticos por seguirem uma sequencia lógica $\mathrm{e}$ sistematizada de atividades que levam a geração de soluções alternativas para um determinado problema. Back (et al. 2008) apresenta três métodos (Quadro 02)nesta categoria: o método da Síntese Funcional; o Método da Matriz Morfológica (Figura 01); e o Método da Análise de Valor.

\section{Quadro 02: métodos intuitivos de Geração de Alternativas.}

\begin{tabular}{|c|c|}
\hline $\begin{array}{l}\text { Síntese } \\
\text { Funcional }\end{array}$ & $\begin{array}{l}\text { Especialmente bem sucedido para a concepção de sistemas técnicos, equipamentos } \\
\text { ou aparelhos que têm por função executar um processo de transformação ou uma } \\
\text { sequência de operações (PAHL e BEITZ, 1996). Segue os passos: 1)Formular o } \\
\text { problema ou a função global do sistema; 2)Estabelecer um fluxo de funções do } \\
\text { problema; 3)Pesquisar os diversos princípios de solução para cada função } \\
\text { estabelecida; 4)Arranjar diferentes combinações entre os princípios para formar } \\
\text { concepções alternativas para o problema global; 5)Selecionar as concepções viáveis. }\end{array}$ \\
\hline $\begin{array}{l}\text { Matriz } \\
\text { Morfológica }\end{array}$ & $\begin{array}{l}\text { Consiste em uma pesquisa sistemática de diferentes combinações de elementos e } \\
\text { parâmetros com o objetivo de encontrar uma nova solução para o problema. Após a } \\
\text { formulação do problema, obtém-se um conjunto de especificações de projeto do } \\
\text { sistema a ser desenvolvido. A seguinte sequência de passos é sugerida: 1)Identificar } \\
\text { as funções ou operações e parâmetros do produto ou processo; 2)As funções mais } \\
\text { gerais (1a coluna da tabela) podem ser desdobradas funções secundárias (2a coluna } \\
\text { da tabela); 3)Buscar princípios de solução alternativos para cada operação ou } \\
\text { parâmetro (colunas seguintes); 4)Combinar os princípios de solução a busca de } \\
\text { soluções ou concepções alternativas para o problema formulado. Esta combinação } \\
\text { adota o principio de solução de uma linha com os princípios das demais linhas, } \\
\text { assim, rapidamente pode-se gerar um número elevado de concepções de projeto; } \\
\text { 5)Avaliar e selecionar as concepções. Algumas combinações são tecnicamente } \\
\text { excluídas pela incompatibilidade entre os princípios de solução ou inviabilidade } \\
\text { técnica de execução; } 6 \text { )Estabelecer o leiaute e descrever a concepção. A montagem } \\
\text { da matriz gráfica, apesar de mais trabalhosa, traz grandes facilidades com relação a } \\
\text { uma matriz verbal especialmente na fase de montar o leiaute da concepção final. }\end{array}$ \\
\hline $\begin{array}{l}\text { Método de } \\
\text { Análise de } \\
\text { Valor }\end{array}$ & $\begin{array}{l}\text { Entendido como uma revisão completa do projeto do produto, visa introduzir } \\
\text { modificações traduzidas através de novos princípios de solução, tecnologias, } \\
\text { materiais e processos com o objetivo de melhorar a qualidade ou agregar valor ao } \\
\text { produto. Segue as seguintes etapas: 1)Preparação: escolher o produto, determinar } \\
\text { o objetivo, compor um grupo de trabalho e planejar as atividades; 2)Coleta da } \\
\text { Informação: obter as informações gerais da situação atual do produto e levantar os } \\
\text { processos e custos; 3)Análise do produto: Essa etapa tem por finalidade identificar a } \\
\text { real função de cada parte ou unidade de custo e identificar falhas ou deficiências no } \\
\text { produto. 4)Geração de soluções - criatividade: Esse passo visa buscar ideias que } \\
\text { venham a reduzir custos ou melhorar os processos para cada unidade ou parte do } \\
\text { produto. 5)Avaliação e seleção das soluções: Concluída a fase da criatividade, é } \\
\text { necessário o julgamento das ideias. Pode-se decompor essa etapa nas seguintes: } \\
\text { formular e desenvolver alternativas; viabilizar tecnicamente; viabilizar } \\
\text { economicamente; e decidir pela melhor. 6)Fase de planejamento: Apresentar e } \\
\text { aprovar a proposta; planejar e acompanhar a implementação (BACK et al,2008) }\end{array}$ \\
\hline
\end{tabular}




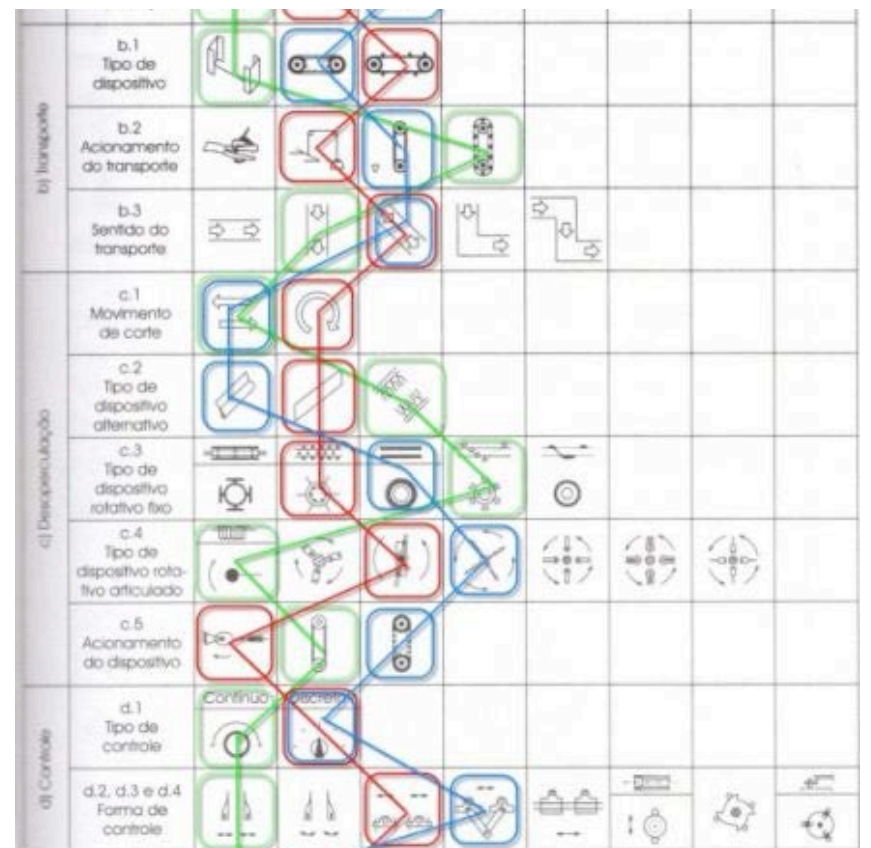

Figura 01: Exemplo de combinação dos princípios de solução. Fonte: Adaptado de Resin (1989 apud Back et al, 2008)

O estudo da criatividade auxilia no processo de geração de soluções de e, de acordo com Back et al. (2008), os métodos apresentados induzem o indivíduo ou grupo a gerar uma grande quantidade de ideias, aumentando as probabilidades de se obter uma solução boa, inovadora, ou, ao menos, leva à tarefa ou ao exercício de combinar, comparar e selecionar soluções.

\section{METODOLOGIA}

O presente capítulo apresenta a aplicação prática de desenhos como ferramenta de criação no processo geração de concepções de projeto. A técnica utilizada foi a Matriz Morfológica. Como objeto de trabalho para o emprego das técnicas de criação teve-se a resolução de um problema não estruturado: o transporte urbano de crianças de 0 a 1 anos em curtas distâncias, com o objetivo avaliar esta técnica e o uso de desenhos em diferentes momentos. Para o presente estudo, estes momentos foram divididos segundo três objetivos: para expressão e representação gráfica esquemática de ideias; para comunicação entre os membros da equipe de projeto e demais equipes, assim como para associações e refinamento de concepções de projeto; para apresentação visual das propostas e detalhamento por meio que diagramas funcionais.

\subsection{Matriz Morfológica}

Conforme explicado anteriormente, o método da Matriz Morfológica consiste na pesquisa sistemática de diferentes combinações de elementos e parâmetros com o objetivo de encontrar uma nova solução para o problema de acordo com as funções e subfunções especificadas para o sistema/produto. Após as discussões realizadas em uma primeira etapa de geração inicial de ideias (brainstorming e brainwriting), foram elencadas as funções e subfunções para resolução do problema proposto. O Quadro 03 apresenta o desdobramento das funções do produto. 
Com o objetivo de gerar diferentes concepções de projeto, foram desenhados no mínimo três princípios de solução para as funções e subfunções elencadas para posterior combinação dos princípios na busca de alternativas para a resolução do problema formulado. Como o objetivo da proposta era testar a eficiência e eficácia do emprego de desenhos nas técnicas propostas, os mesmos foram feitos em grande formato montando uma enorme matriz morfológica, de acordo com a ordem elencada no Quadro 03, para melhor visualização e discussão entre os três membros da equipe.

Quadro 03: desdobramento das funções e desenhos gerados - Matriz Morfológica.

\begin{tabular}{|l|l|}
\hline \multicolumn{1}{|c|}{ Função } & \\
\hline $\begin{array}{l}\text { Conduzir } \\
\text { Deslocar }\end{array}$ & $\begin{array}{l}\text { Prender a Criançápios de Solução } \\
\text { Proteger a Criança }\end{array}$ \\
\hline $\begin{array}{l}\text { Proporcionar } \\
\text { Segurança }\end{array}$ & \\
\hline Acomodar a Criança & \\
\hline Carregar o Produto & Facilitar Limpeza \\
\hline $\begin{array}{l}\text { Permitir } \\
\text { Portabilidade }\end{array}$ & $\begin{array}{l}\text { Personalizar a aparência } \\
\text { Personalizar acessórios }\end{array}$ \\
\hline $\begin{array}{l}\text { Permititar a Substituição de partes } \\
\text { Prmazenamento }\end{array}$ & Facilitar a desmontagem \\
\hline Permitir Manutenção & \\
\hline
\end{tabular}


Desta forma, os princípios desenhados foram combinados conforme as cores das setas aplicadas na Matriz Morfológica. Foram geradas cinco alternativas que combinaram diferentes princípios segundo as orientações anteriormente apresentadas. Foram eliminadas combinações tecnicamente incompatíveis ou de inviabilidade técnica para execução. Uma vez concebidas, as cinco alternativas foram detalhadas em diagramas funcionais com o uso de renderings manuais para sua apresentação e avaliação, conforme o Quadro 04.

Quadro 04: Diagramas funcionais e apresentação das alternativas desenvolvidas a partir da Matriz Morfológica.

Alternativa 01

A partir da Matriz Morfológica finalizada, as concepções geradas poderiam ser empregadas em demais ferramentas de seleção e refinamento de alternativas, até se chegar a seleção e detalhamento final da proposta. Segundo esta aplicação, o emprego de desenhos em ferramentas de criação para a geração de concepções de projeto dividiu-se em: para expressão e representação gráfica de ideias; para comunicação, assim como para associações e refinamento de concepções de projeto; para apresentação visual das e detalhamento.

Primeiramente, utilizou-se de técnicas de desenho expressionais mais para geração de ideias do que para comunicação, uma vez que cada ideia gerada era apresentada verbalmente. Assim, os desenhos utilizados nesta etapa inicial não tinham o caráter de representação operacional ou para documentação de projeto, pois eram gerados de forma mais livre como um esboço de um conceito, ou seja, de forma muito simples e normalmente requerendo explicação verbal e/ou escrita (PIPES, 2010). Estas representações geravam novas ideias a partir destas, para um refinamento natural das 
ideias em relação aos desenhos anteriores, indo além da representação para comunicação/expressão e sim para reflexão-na-ação.

Enquanto técnica criativa, o brainstorming e brainwriting contribuíram mais para geração de novas ideias e discussão das mesmas do que para geração de alternativas concretas. Contribuiu ainda para definição das diretrizes e critérios para o desenvolvimento de soluções por meio da matriz morfológica. Entretanto, na matriz morfológica, o emprego de desenhos cumpriu um papel bem mais concreto representando princípios de soluções, funcionamento de sistemas e suas relações, possibilitando a avaliação e seleção entre as alternativas geradas.

Como técnica criativa para geração de alternativas de projeto a Matriz Morfológica com o uso dos desenhos possibilitou estabelecer a configuração formal e funcional além de descrever detalhadamente as concepções desenvolvidas para posterior avaliação sistematizada. Assim, novamente ocorre a reflexão-na-ação em diferentes fases do processo criativo no PDP.

\section{CONSIDERAÇÕES FINAIS}

A partir da revisão bibliográfica realizada acerca dos processos criativos, das técnicas de criação e do emprego de desenhos no PDP é possível evidenciar a contribuição da representação gráfica ao longo de todo processo de projeto como mecanismo de criação, expressão, reflexão, refinamento e comunicação.

Ressalta-se então a importância de aprofundar o estudo da inter-relação entre desenho e técnicas criativas no PDP, como ferramenta de apoio à geração de ideias e concepções de projeto, assim como para a seleção, refinamento e apresentação destas.

Conforme relatado anteriormente, o PDP requer conhecimentos técnicos e teóricos para obtenção de bons resultados e o emprego de técnicas criativas sistemáticas auxilia a orientar a geração de alternativas que não necessariamente desconsiderem a intuição e o repertório pessoal e profissional. Ao contrário, potencializa o processo criativo ao guiar o desenvolvimento do projeto ao mesmo tempo em que possibilita a avaliação objetiva dos resultados.

\section{REFERÊNCIAS}

ARNHEIM, Rudolf. Visual Thinking. California: University of California Press, 1997.

ALENCAR, Eunice Soriano de. A Gerência da Criatividade. São Paulo: Makron, 1996.

BACK, N.; OGLIARI, A.; DIAS, A.; SILVA, J. C. Projeto integrado de produtos: planejamento, concepção e modelagem. Barueri, SP: Manole, 2008.

BAXTER, Mike. Projeto de produto: guia prático para o design de novos produtos. $2^{\circ}$ ed. São Paulo: Edgard Blücher, 2000.

BODEN, Margareth A. Dimensões da Criatividade. Porto Alegre: Artes Médicas Sul, 1999.

BOMFIM, Metodologia para Desenvolvimento de Projeto. João Pessoa: Editora da UFPB, 1995.

BRASIL. Resolução $n^{\circ} 5$, de 8 de março de 2004. Aprova as Diretrizes Curriculares Nacionais do Curso de Graduação em Design e dá outras providências. Diário Oficial da União, Brasilia, DF, 15 mar. 2004. Disponível em < http://portal.mec.gov.br/cne/arquivos/pdf/CES02-04.pdf>. Acesso em: 15 nov. 2013. 
DE BONO, Edward. O Pensamento Criativo. Petrópolis: Vozes Ltda. 1970.

GARDNER, Howard. Mentes que mudam: a arte e a ciência de mudar as nossas ideias e a dos outros. Porto Alegre: Artmed/Bookman, 2005.

GOMES, Luiz Vidal Negreiros. Criatividade: projeto < desenho > produto. Santa Maria: sCHDs, 2004.

GOMES, Luiz Vidal Negreiro. et al. Criatividade e projeto de produto: um modelo para geração de alternativas. GRAPHICA. Rio de Janeiro. Out. 2011.

KNELLER, George Frederick. Arte e Ciência da Criatividade. São Paulo: Ibrasa, 1978.

LÖBACH, Bernd. Design industrial: bases para a configuração dos produtosindustriais. São Paulo: Edgard Blucher, 2001.

LUBART, Todd. Psicologia da Criatividade. Porto Alegre: Grupo A. 2007.

PAHL, G; BEITZ, W. Engineering design: a systematic approach. 2ed. London, Springer Verlag, 1996.

PEI, E., CAMPBELL, R.I. and EVANS, M.A.. A Taxonomic Classification of Visual Design Representations Used by Industrial Designers and Engineering Designers. The Design Journal, 14 (1), 2011: pp. 64-91.

NOVAES, Maria Helena. Psicologia da Criatividade. Petropolis: Vozes Ltda. 1971.

OSTROWER, Fayga. Criatividade e Processos de Criação. $25^{\circ}$ ed. Petropolis: Vozes Ltda. 2010.

PIPES, Alan. Desenho para Designers. São Paulo: Editora Blucher, 2010.

SCHÖN, D. A. Educando o Profissional Reflexivo: um novo design para o ensino e a aprendizagem. Porto Alegre: Artmed, 2000.

SUWA, Masaki; TVERSKY, Barbara. Thinking with Sketches. In: MARKMAN, Arthur; TVERSKY, Barbara. et al. Sketches for Design and Designs of Sketches. Human Behaviour in Design. 2003. P. 79-82. 